\title{
ANÁLISIS DE LA CADENA DE VALOR DE LA MACA
}

Juan Carlo López R. *

\section{INTRODUCCIÓN}

En la actualidad nuestro país se enfrenta a un problema concreto, real y cada vez mayor. Un reto que se llama: GLOBALIZACION. Si no le damos mayor valor agregado a nuestras exportaciones nuestro problema se ahondará aun más.

Se debe iniciar estudios de proyectos que consigan incentivar la transformación de nuestros recursos naturales. Asimismo se debe promocionar nuestros productos en el exterior utilizando para ello todas las facilidades de INTERNET, resaltando todas nuestras ventajas competitivas esto es PARTIENDO DEL VALORNUTRITIVO - para el caso de la agroindustria.

Sólo así mejoraremos el nivel de vida de los pobladores del campo, promoviendo la creación de más puestos de trabajo.

Pero nuestro desarrollo debe ser sostenible y teniendo en cuenta la conservación el medio ambiente.

Siendo el sector agroindustrial prioritario para aprovechar los recursos naturales y posibilitar su exportación a los mercados internacionales; las estrategias estarían orientadas a generar negocios viables y la creación de fuentes de trabajo en el sector de las PYMES.

\section{PROPUESTA : LA INDUSTRIALIZACIÓN DE LA MACA Y SU EXPORTACIÓN.}

Conocer el mercado es uno de los primeros pasos para elaborar un proyecto y para el caso de la

Cuadro 1. Principales Países Importadores

\begin{tabular}{|c|c|c|c|c|}
\hline \multicolumn{5}{|c|}{ Principales p a ises limportadores } \\
\hline \multirow{2}{*}{ Países } & \multicolumn{2}{|c|}{ Volumen en $\mathrm{Kg}$. } & \multicolumn{2}{|c|}{ FOB USS } \\
\hline & 1999 & 1998 & 1999 & 1998 \\
\hline EEUU: & 30297.81 & 89600.64 & 345199.64 & 865340.98 \\
\hline Japón & 48815.53 & 3577.6 & 842710.05 & 55161.8 \\
\hline Italia & 380 & 286.79 & 3202.5 & 5736.44 \\
\hline España & 323 & 2009.57 & 2477,73 & 11728.79 \\
\hline Alemania & 650 & 37.52 & 9378.23 & 222 \\
\hline Otros & & & & \\
\hline (América) & 1564.24 & 2540.69 & 17197.14 & 33005.75 \\
\hline Otros & & & & \\
\hline (Europa) & 2995.84 & 669.72 & 71501.6 & 16937.2 \\
\hline Otros (Asia) & 975.3 & 7.68 & 32323 & 23.16 \\
\hline 無OTAI & 860017 & 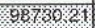 & 2358989 & $988456 \%$ \\
\hline
\end{tabular}

Fuente: Aduanas

Estudiante de la Facultad de Ingenieria Industrial UNMSM. Equipo de Investigación de Tecnologia Industrial agroindustria es vital. Nosotros debemos conocer por ejemplo que alrededor del $91 \%$ de nuestras exportaciones de maca se dirigen a los Estados Unidos de Norteamérica y al Japón seguido por países como Alemania y España entre los principales. A continuación veamos algunos datos importantes.

Asimismo es importante conocer la Composición Nutritiva de la Maca que nos ayuda a entender su importancia en la dieta de:

1.Los niños, porque contribuye al desarrollo normal de su constitución física y mental, además, la Maca ayuda a la formación de los huesos por su alto contenido de fósforo, calcio, zinc, vitamina $E$ y otros.

2.Los adultos, porque reduce el stress, restablece la capacidad y equilibrio corporales e intelectuales, es suplemento en actividades deportivas, aumenta la capacidad inmunitaria del organismo, ayuda a la curación de los nervios, el raquitismo, la mal formación de los huesos, artritis, la osteoporosis, la descalcificación, el reumatismo, la anemia y facilita el funcionamiento y la curación del hígado.

Las personas de la tercera edad, porque retarda el envejecimiento, el deterioro de la piel y todos los órganos. Además es vigorizante, reconstituyente, rejuvenecedor y aumenta la capacidad inmunitaria del organismo

En instituciones de otros países la maca ya es consumida en importantes cantidades como es el caso de la NASA quienes acogieron el proyecto de la

Cuadro 2. Composición Nutritiva de la Maca

\begin{tabular}{|c|c|}
\hline \multicolumn{2}{|c|}{  } \\
\hline Componente & Promedio \\
\hline Proteínas & $13 \%$ \\
\hline Almidón & $20.50 \%$ \\
\hline Grasa & $7.59 \%$ \\
\hline Fibra & $4.20 \%$ \\
\hline Calorías & $372.76 \mathrm{Kcal}$ \\
\hline \multicolumn{2}{|l|}{ Minerales } \\
\hline Calcio & $258.00 \mathrm{mg}$. \\
\hline Fósforo & $189.96 \mathrm{mg}$. \\
\hline Hierro. & $15.41 \mathrm{mg}$. \\
\hline \multicolumn{2}{|l|}{ Vitaminas } \\
\hline Caroteno & $0.07 \mathrm{mg}$. \\
\hline Tiamina & $0.17 \mathrm{mg}$ \\
\hline Rivoflavina & $0.39 \mathrm{mg}$. \\
\hline Ácido Ascórbico & $2.86 \mathrm{mg}$. \\
\hline
\end{tabular}

Fuente: Ministerio de Agricultura 
Dra. Chacón de la UNMSM, sobre el consumo de la maca para mejorar la dieta de los astronautas. Y más aún el astronauta Carlos Noriega señaló que "los científicos del Perú deben enviar sus proyectos a la NASA".

\section{COSTOS DE INVERSIÓN}

El costo de cultivo de Maca por hectárea es de aproximadamente: 4049 soles.

El costo de combustible del camión trasportador de $38 T N$ de maca de Junin (principal productor de la Maca) hacia a Lima es de aproximadamente: 35 soles.

La inversión mínima aproximada en dólares para iniciar una Pequeña Planta procesadora de Néctar de Maca es la siguiente:

\begin{tabular}{|l|r|}
\hline \multicolumn{2}{|c|}{ Cuadro 3. Inversión } \\
\hline \multicolumn{2}{|c|}{ Inversión } \\
\hline Activos Fijos & 95104.10 \\
\hline Intanibles & 27500.00 \\
\hline Capital de Trabajo & 45717.43 \\
\hline Total Inversión & 168321.53 \\
\hline
\end{tabular}

Fuente: Elaboración propia.
Según la información del cuadro 3 podemos pronosticar nuestras ganancias asumiendo un marco de estabilidad económica.

A partir de la figura 1 podemos concluir que la Industrialización de la maca es el negocio más rentable.

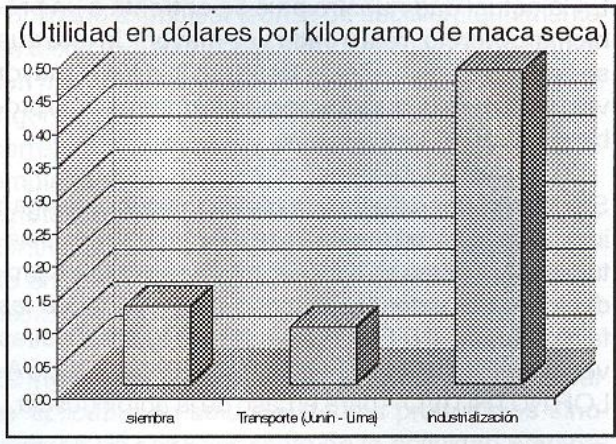

Figura 1. Cadena de Valor para el primer año

Para promocionar la maca en todo el Mundo he creado un sitio Web cuya dirección es:

http://commununities.msn.es/ALIMENTO NUTRITIVOLAMACADELPERU

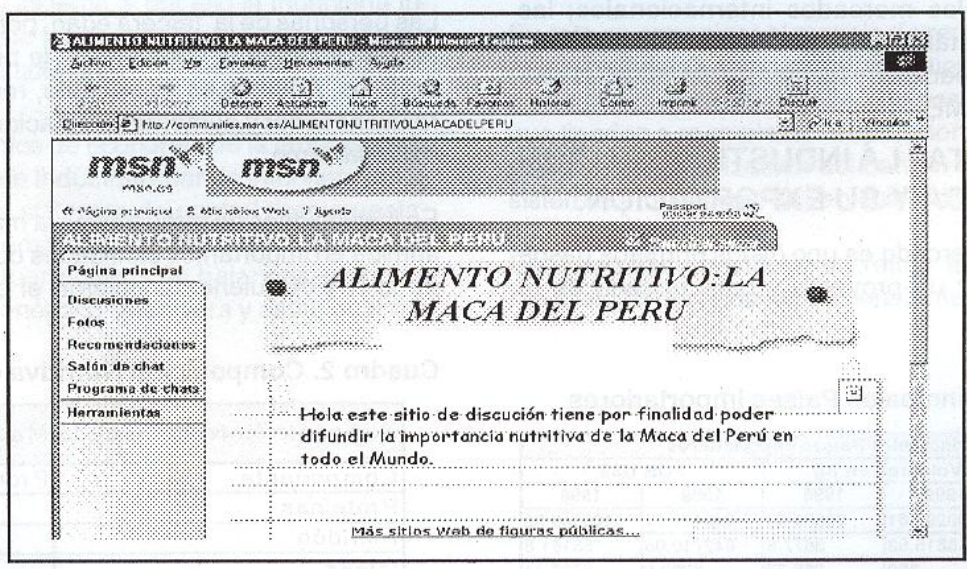

